\title{
CISTO ARACNÓIDEO EXTRADURAL DO CANAL ESPINAL
}

\author{
Nelson Pires Ferreira * \\ José B. TeixeIra FILHO **
}

Os cistos extradurais do canal espinal são raros como causa de compressão medular. Esta condição patológica é caracterizada pela presença de cisto de aracnóide extradural comunicante com o conteúdo liquórico subaracnóideo através de pequena solução de continuidade da dura-mater. O aumento do volume do cisto pode condicionar, com o decorrer dos anos, compressão medular e/ou radicular. A revisão da literatura disponível mostra um número

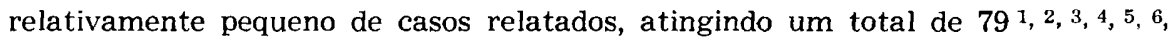
7,8 . Face a pouca freqüência dessa ocorrência patológica e a inexistência de publicação nacional julgamos oportuna esta comunicação.

\section{O B S E R V A Ç Ã O}

DTL, com 49 anos de idade, sexo masculino, brasileiro, internado em 18-03-71, queixando-se de dificuldade para andar, perda de força e de sensibilidade nos membros inferiores. $O$ paciente informou que desde há um ano vem apresentando falta de força nos membros inferiores que se acentuou progressivamente, o mesmo ocorrendo com a sensibilidade. Datam da mesma época parestesias nos pés e na região glútea, disúria, obstipação e impotência sexual. No passado mórbido apenas doenças próprias da infância. Exame clínico-neurológico - O exame dos diversos aparelhos resultou normal; Pressão arterial 120/70; Pulso $80 \mathrm{bpm}$. Exames de laboratório - hemograma, glicemia, dosagem de uréia, soro-diagnóstico de lues e exame comum de urina, sem anormallidades. Marcha espástica, diminuição da motilidade voluntária e da força muscular nos membros inferiores, mais acentuada à esquerda, onde não são possíveis movimentos de flexão, extensão, addução e abdução do pé. Impossivel a abdução das coxas. Hipertonia em extensão nos membros inferiores, mais acentuada à esquerda. Reflexos profundos exaltados nos membros inferiores,mais intensamente à esquerda onde há policinésia. Clono do pé e sinal de Babinski, bilateralmente. Reflexos cutâneo-abdominais inferiores e crematéricos abolidos. Resposta de triplice retirada à esquerda. Hipoestesia superficial de T12 para baixo bilateralmente, mais acentuada à esquerda, havendo anestesia dessas formas de sensibilidade nos metâmerọs T12 e L1 à esquerda. Sensibilidade profunda conservada. Em suma, paraparesia sensitivo-motora espástica com nivel sensitivo em T12, com comprometimento mais acentuado no membro inferior esquerdo. Exame do liquido céfalorraqueano - Raquemanometria normal nāo havendo bloqueio; células $1,2 / \mathrm{mm}^{8}$; proteinas 30mg\%; reações globulinicas negativas, reaçōes para sifilis a cisticercose negativas; glicose $55 \mathrm{mg} \%$; cloretos $120 \mathrm{mEg} / 1$. Radiografias da coluna vertebral

Trabalho realizado no Instituto de Neurocirurgia de Porto Alegre: * Professor Assistente da Faculdade de Medicina da UFRGS e Membro do Instituto de Neurocirurgia; ** Médico Residente. 
- Erosão dos pediculos vertebrais com alargamento do espaco interpedicular de $T_{8}$ a $T_{12}$, mais nitido entre $T_{11}$ e $T_{12}$; erosão dos corpos vertebrais na sua face posterior, condicionando um aspecto encurvado e aumento do diâmetro do canal raqueano no sentido ântero-posterior a êsse nivel. Mielografia (Fig. 1)
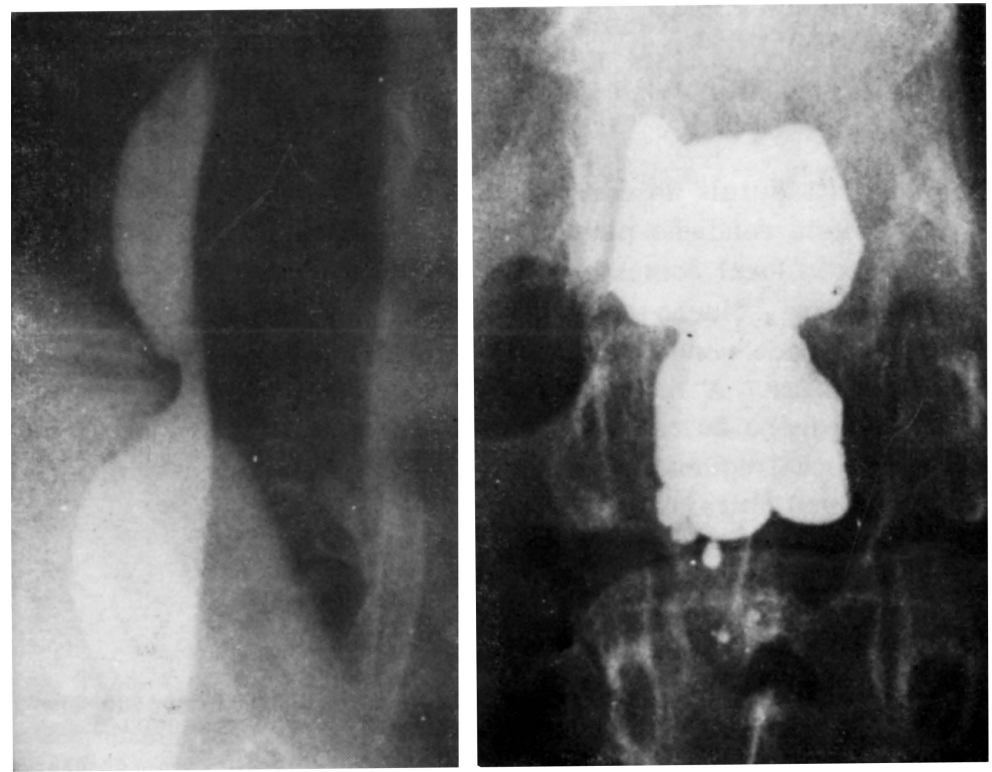

Fig. 1 Caso D.T.L. À esquerda, Mielografia de perfil, com raio horizontal, mostrando aumento do diâmetro ânteroposterior do canal raqueano a custa de erosão dos corpos vertebrais ao nivel de T10-T12; à direita mielografia em AP, com o paciente em decúbito ventral, mostrando o alargamento do canal à custa da erosão dos pediculos vertebrais (nivel T12-L1)

Intervenção cirúrgica - Laminectomia de T10 a T12. As lāminas posteriores se mostravam muito adegalçadas, especialmente as da vértebra T11. Durante a remoçāo das lâminas posteriores houve saida de liquido procedente de cisto subjacente que pulsava com a frequência dos movimentos respiratórios. Após a remoção das lâminas posteriores foi jdentificado grande cisto com profundidade de $2 \mathrm{~cm}$ e largura de $4 \mathrm{~cm}$, que foi esvasiado por aspiração. Após o esvasiamento notou-se a duramater muito adelgasada, permitindo ver, por transparência, a medula e seus vasos. A cavidade do cisto se estendia a $9 \mathrm{~cm}$ acima e $3 \mathrm{~cm}$ abaixo da laminectomia. A parede posterior do cisto foi removida em quase toda a sua extensão, não sendo identificado o ponto de comunicação com o espaço subaracnoideo. O exame histopatológico da parede do cisto mostrou tratar-se de tecido conjuntivo apresentando numerosos grânulos de hemossiderina. O pós-operatório transcorreu sem anormalidades, havendo discreta piora do quadro neurológico nos três dias que se seguiram à intervenção cirúrgica. Alta hospitalar 21 dias após a intervenção, com discretas melhoras motoras e sensitivas, especialmente na marcha. 
A maior incidência dos cistos de aracnóide recae na segunda década da vida. Na maioria dos casos as lesões se estendem a mais de uma vértebra, com uma freqüência nitidamente maior na coluna torácica e, nesta, nas suas porções inferiores. E rara a localização cervical e sacra ${ }^{1},{ }^{3}$. A queixa pode ter curta duração, apenas algumas semanas, ou cronificar-se por alguns anos. A remissão da sintomatologia pode ocorrer não sendo, entretanto, freqüente. A dor é freqüente, por vezes surda, na região posterior da coluna vertebral ou aguda, irradiando-se com características segmentares. O quadro neurológico é, com freqüência, o de uma compressão medular com intensidade variável. Os sinais motores são mais constantes que os sensitivos, mas nível sensitivo pode ser encontrado. Uma distribuição segmentar de perda de sensibilidade pode aparecer quando há envolvimento de raizes raqueanas. $\mathrm{Na}$ maioria dos casos o estudo radiológico da coluna vertebral mostra erosão dos pedículos ou dos corpos vertebrais. O estudo mielográfico permite diagnóstico pré-operatório seguro.

Os cistos extradurais são considerados por Elsberg e col., por Nugent e Rexed, citados por Gortvai ${ }^{3}$ e por Bergland ${ }^{1}$ como de origem congênita. É razoável supor que estes cistos, que se comunicam com o espaço subaracnoide junto à linha média, sejam de origem congênita pois assemelham-se a um estado disráfico no qual há pequenas falhas de fusão durante a fase embrionária. Essas pequenas soluções de continuidade dural permitiriam a passagem de aracnoide que formaria os cistos. A concomitância de cisto de aracnoide e outras malformaçōes do sistema nervoso fortalece a teoria congênita. A freqüência com que traumatismos são referidos na história desses pacientes, lembra a possibilidade de interferência causal ou direta. Meredith, citado por Gortvai ${ }^{3}$, tendo encontrado grânulos de hemossiderina em dois casos com história prévia de traumatismos, lembra a possibilidade destes como causa, apesar de ser possivel a ocorrência de hemorragias pós-traumáticas em cistos pré-existentes. A teoria traumática não pode ser desprezada de todo por ter sido assinalado, após intervenções cirúrgicas espinais, o aparecimento de cistos de aracnoide.

Os cistos só passam a produzir sintomas quando alcançam um tamanho considerável. Os fatores que condicionam o seu aumento são a pressão hidrostática do líquido cefalorraqueano, a osmose carreando líquido para o interior do cisto e a secreção das paredes do mesmo. Parece, entretanto, que o elemento mais importante é a abertura valvulada na comunicação do cisto com o espaço subaracnoideo, condicionando o seu crescimento progressivo. A osmose de água pode atuar como coadjuvante no acréscimo de volume do cisto, quando a abertura é valvular ou após o fechamento da mesma. $O$ papel secretório das paredes do cisto não é fato comprovado ${ }^{3}$.

A ocorrência de cifose é assinalada em um terço dos casos aproximadamente, sendo possivel que essa deformação decorra da paralisia segmentar dos músculos eretores da coluna vertebral. Outra possibilidade seria a destruição óssea motivada pelo cisto ou, mais tardiamente, pela própria laminectomia. 
A terapêutica consiste na remoção do cisto ou na ressecção, a mais ampla possivel, de sua parede posterior. A sutura ou o tamponamento com músculo da comunicação condiciona a cura completa. O prognóstico, de acordo com a revisão da literatura, é regular. Gortvai ${ }^{3}$ obteve bons resultados em três dos cinco casos por ele operados.

R E S M O

E relatado o caso de um paciente que apresentava paraparesia sensitivo-motora evolutiva, datando de um ano. As radiográficas da coluna vertebral e mielografia permitiram o diagnóstico de cisto de aracnóide extradural do canal espinal de localização torácica, que foi confirmado pelo ato cirrúrgico. Os autores revisam a literatura assinalando 76 casos já publicados. São comentadas a incidência do processo patológico nos diversos grupos etários, sua localização ao longo do canal raqueano, a evolução do quadro clínico, a etiologia e a fisiopatologia do crescimento do cisto, o diagnóstico, a terapêutica e o prognóstico.

\section{S U M M A R Y}

\section{Arachnoideal extradural cyst of the spinal canal. A case report}

The case of a pacient with thoracic arachnoideal cyst is reported. There was a neurological picture of a spinal cord compression in thoracic level with analgesia and anesthesia in $\mathrm{T} 12$ and $\mathrm{L} 1$ at left. Radiographs showed compression of the pedicles with widening of interpedicular spaces of the eight to twelfth thoracic vertebrae. The myelogram and the laminectomy confirmed the hypothesis of aracnoideal cyst. This case of extradural cyst of the spinal canal is added to the 76 previously described in the literature. The incidence, etiology, phisiopathology, clinical-picture, diagnosis, surgical treatment and prognosis are discussed.

\section{REFERENCIAS}

1. BERGLAND, R. M. - Congenital intraspinal extradural cyst. J. Neurosurg. 28:495, 1968 .

2. DASTUR, H. M. - The radiological appearance of spinal extradural arachnoideal cysts. J. Neurol. Neurosurg. Psychiat. 26:231, 1963.

3. GORTVAI, P. Extradural cysts of the spinal canal. J. Neurol. Neurosurg. Psychiat. 26:223, 1963.

4. HEPPNER. F. \& DIEMATH, H. E. - Gibt es Meningozelen bei geschlossenem Wirbelkanal? Zentralblatt f. Neurochirurgie 20:227, 1960.

5. ONO, K. NAKAGAWA, K.; SUGINO, T. \& OMI, T. - Four cases of arachhoid cyst with spinal symptoms. Orthop. Surg. (Tokyo) 21:116, 1970.

6. SWANSON, H. S. \& FINCHER, E. F. - Extradural arachnoid cysts of traumatic origin. J. Neurosurg. 4:530, 1947.

7. TOURNOUX, M. P. \& HERMO, J. F. - Pseudo-acropathie ulcéromutilante et malformation kystique arachnoidienne lombaire. Neuro-chirurgie 16:436, 1970.

8. ZANDER, E.; SÉQUIER, M. \& PERRIG, A._- Contribution à l'étude des kystes méningés extra-duraux de la région dorso-lombaire. Neurochirurgie 13:585, 1967. 